\title{
PET and SPECT in psychiatry: the past and the future
}

\author{
Marco Pagani $^{1,2} \cdot$ Sara Carletto ${ }^{3} \cdot$ Luca Ostacoli $^{3}$ \\ Published online: 25 July 2019 \\ (C) Springer-Verlag GmbH Germany, part of Springer Nature 2019
}

The recent technical progresses in PET have the potential to broaden the spectrum of applications of nuclear medicine for both research and clinical investigations.

Dynamic scans at rest, assessing ${ }^{18} \mathrm{~F}-\mathrm{FDG}$ uptake in the first minutes after bolus injection, allow to capture the cortical and subcortical distribution occurring at the same time. In these first minutes, in which the most of the radiopharmaceutical is extracted by the brain before reaching a plateau after about thirty minutes, ${ }^{18} \mathrm{~F}-\mathrm{FDG}$ uptake, representing neuronal and glial activity, is consistently couple with brain perfusion [1]. The substantial advancements improving the sensitivity and time resolution of the cameras have paved the way to the implementation of the so-called functional PET, a new methodology implying a slow and constant infusion allowing to monitor tracer uptake during time and to measure within the same session its distribution at rest and while performing a task [2]. Furthermore, dual-phase amyloid-PET scans exploiting the high lipophilicity of the radiopharmaceuticals make of the early dynamic acquisition phase a good perfusion surrogate and a topographical/functional biomarker reflecting disease progression, while the late-phase corresponds to the pathophysiological state [3].

It is in this frame that, in the August 2019 issue of the European Journal of Nuclear Medicine and Molecular Imaging, it is reported an original and well-conducted study aiming at describing in fifteen soldiers suffering from posttraumatic stress disorder (PTSD) following war combat the functional changes occurring before and after eye movement

This article is part of the Topical Collection on Editorial

Sara Carletto

sara.carletto@unito.it

Institute of Cognitive Sciences and Technologies, CNR, Rome, Italy

2 Medical Radiation Physics and Nuclear Medicine, Karolinska University Hospital, Stockholm, Sweden

3 Department of Clinical and Biological Sciences, University of Turin, Regione Gonzole 10, 10043 Orbassano, TO, Italy desensitization and reprocessing (EMDR), a trauma-focused psychotherapy promoting the reprocessing of dysfunctionally stored information in traumatized patients [4]. In order to disclose such neurobiological changes, they were exposed from 10 minutes before to 7 minutes after ${ }^{18} \mathrm{FDG}$ injection to a virtual reality war scene with strong autobiographic connotations. Therefore, the PET images acquired thirty minutes after injection represented the distribution of metabolism in the minutes peri-injection in which the emotional stimulus was administered. This procedure, performed during the symptomatic phase, was repeated after EMDR therapy, thus allowing to detect the metabolic changes associated with symptoms remission. Applying this elegant methodology, they were able to speculate on the role of the precuneus in reprocessing traumatic memories. After EMDR therapy, its modulation of anxious and fearful states made patients perceiving their traumatic event at a cognitive level without overwhelming emotionality.

In order to elicit an emotional response and to investigate in real time the regions hyper- or hypo-activated in association with symptoms, most of neuroimaging studies in psychiatry have been performed by administering during the recording of the functional activity the so-called script $[5,6]$. When investigating PTSD, the script is either an autobiographical narrative of the traumatic event to be read from a written text or, more frequently, to be listened by an audiotape or, as in the Rousseau et al. study, the exposure of the patient to stimuli (images or sounds) correlated to the event itself. Aiming at disclosing the neurobiological correlates of PTSD, the first PET studies were performed in Vietnam veterans and in women abused during childhood by injecting ${ }^{15} \mathrm{O}$-water upon script listening [7, 8]. Subsequently, the same methodology was successfully implemented in SPECT studies in which the script was administered away from the camera gantry a few minutes pre- and post-injection assessing the blood flow distribution by ${ }^{99} \mathrm{Tc}-\mathrm{HMPAO}[9,10]$ or ${ }^{99} \mathrm{Tc}-\mathrm{ECD}[11]$. All these studies consistently reported in association with symptoms of hyperarousal, avoidance and re-experiencing (i.e. the typical clinical feature of PTSD), a hyperactivation of limbic system structures, 
i.e. amygdala, and a hypoactivation of cortical structures, i.e. prefrontal cortex $[12,13]$. In the recent past, it has been reported by SPECT [14-16] and EEG [17-19] that trauma-focused psychotherapies, among which EMDR, reverse the functional changes caused by PTSD and normalize the activity in cortical and subcortical structures.

The successful outcome of the Rousseau et al. study replicated the methodology implemented by Chiaravalloti et al. investigating patients with multiple chemical sensitivity (MCS) [20]. They injected ${ }^{18}$ FDG in MCS patients and healthy controls $(\mathrm{HCs})$ three minutes after the inhalation of either neutral or pure olfactory stimuli, prolonging the procedure for six more minutes. Also in this case, PET images acquired thirty minutes after injection represented the metabolic status at the time of the stimulation identifying several cortical regions in which metabolism, evaluated in the two different experimental conditions, differed between MCS patients and HCs.

The innovative PET methodologies described above overcome the disadvantages of functional magnetic resonance imaging (fMRI), the most used methodology in resting-state and functional activation studies in psychiatry [21, 22]. Some of these drawbacks have recently been discussed by Verger and Guedj [23], who pointed out that at single subject level the reproducibility of the studies could be impaired by the low and variable between runs signal-to-noise ratio and by the need of multiple runs. Furthermore, fMRI is sensitive to ferromagnetic artefacts deriving from implantable devices. Also the noise deriving by the coils may bias the experimental inputs and outputs and the tight space within the camera gantry may prevent scanning subjects suffering from claustrophobia. Beyond these technical drawbacks of fMRI, the main advantage of activation studies by ${ }^{18} \mathrm{FDG}-\mathrm{PET}$ is the possibility to perform the investigations outside the camera gantry. This will allow to run the experiments in a more ecological environment with the subjects comfortably positioned, less distracted by all camera-related variables and more focused of the task to be performed.

Moreover, the possibility to run functional neuroimaging investigations by ${ }^{18}$ FDG-PET makes them easier to be carried out and more approachable by nuclear medicine departments when compared with the ones performed producing ${ }^{15} \mathrm{O}$, the radioisotope extensively utilized in the past in the seminal activation studies on the neurobiology of PTSD [24]. In fact, the mandatory proximity of an in-house cyclotron, the equipment needed for ${ }^{15} \mathrm{O}$ gas inhalation or continuous injection, and the need of an operator beside the bed to collect repeated arterial sampling restrict the possibility to perform the experiments to a very limited amount of centres.

PET activation studies in psychiatry may in the next future also benefit from the introduction of cameras with a temporal resolution of seconds. In fact, performing dynamic scans upon the neuronal activation elicited by the emotional stimuli will add to the information about metabolic distribution also the details about blood inflow enabling to explore the neurometabolic and neurovascular coupling in normal and pathological conditions.

All these potential advantages have to be carefully taken into account by the members of the nuclear medicine community. In a moment in which PET, beyond oncology, is gaining more and more space in neurology [25, 26], functional imaging might contribute to the renaissance of this methodology also in psychiatry. The possibility to perform activation studies with reliable spatial and temporal resolution will attract psychiatrist and psychologist not only for research purposes but, in a near future, also to discriminate between the different psychiatric disorders and to predict the outcome of psychotherapeutic and pharmacological treatments [27-29].

\section{Compliance with ethical standards}

Conflict of interest The authors declare that they have no conflict of interest.

\section{References}

1. Huisman MC, van Golen LW, Hoetjes NJ, Greuter HN, Schober P, Ijzerman RG, et al. Cerebral blood flow and glucose metabolism in healthy volunteers measured using a high-resolution PET scanner. EJNMMI Res. 2012;2:63.

2. Villien M, Wey H-Y, Mandeville JB, Catana C, Polimeni JR, Sander CY, et al. Dynamic functional imaging of brain glucose utilization using fPET-FDG. Neuroimage. 2014;100:192-9.

3. Blomquist G, Engler H, Nordberg A, Ringheim A, Wall A, Forsberg A, et al. Unidirectional influx and net accumulation of PIB. Open Neuroimaging J. 2008;2:114-25.

4. Rousseau PF, Malbos E, Verger A, Nicolas F, Lançon C, Khalfa S, et al. Increase of precuneus metabolism correlates with reduction of PTSD symptoms after EMDR therapy in military veterans: an $18 \mathrm{~F}-$ FDG PET study during virtual reality exposure to war. Eur J Nucl Med Mol Imaging. 2019;46:1817-21.

5. Hölzel BK, Hoge EA, Greve DN, Gard T, Creswell JD, Brown KW, et al. Neural mechanisms of symptom improvements in generalized anxiety disorder following mindfulness training. Neuroimage Clin. 2013;2:448-58.

6. Buchheim A, Viviani R, Kessler H, Kächele H, Cierpka M, Roth G, et al. Changes in prefrontal-limbic function in major depression after 15 months of long-term psychotherapy. PLoS One. 2012;7: e33745.

7. Shin LM, McNally RJ, Kosslyn SM, Thompson WL, Rauch SL, Alpert NM, et al. Regional cerebral blood flow during script-driven imagery in childhood sexual abuse-related PTSD: a PET investigation. Am J Psychiatry. 1999;156:575-84.

8. Bremner JD, Staib LH, Kaloupek D, Southwick SM, Soufer R, Charney DS. Neural correlates of exposure to traumatic pictures and sound in Vietnam combat veterans with and without posttraumatic stress disorder: a positron emission tomography study. Biol Psychiatry. 1999;45:806-16.

9. Liberzon I, Taylor SF, Amdur R, Jung TD, Chamberlain KR, Minoshima S, et al. Brain activation in PTSD in response to trauma-related stimuli. Biol Psychiatry. 1999;45:817-26. 
10. Lindauer RJL, Booij J, Habraken JBA, Uylings HBM, Olff M, Carlier IVE, et al. Cerebral blood flow changes during scriptdriven imagery in police officers with posttraumatic stress disorder. Biol Psychiatry. 2004;56:853-61.

11. Peres JFP, Newberg AB, Mercante JP, Simão M, Albuquerque VE, Peres MJP, et al. Cerebral blood flow changes during retrieval of traumatic memories before and after psychotherapy: a SPECT study. Psychol Med. 2007;37:1481-91.

12. Im JJ, Namgung E, Choi Y, Kim JY, Rhie SJ, Yoon S. Molecular neuroimaging in posttraumatic stress disorder. Exp Neurobiol. 2016;25:277-95.

13. Pagani M, Cavallo M. Neuroimaging in PTSD-related psychotherapies. In: Dierckx R, Ott A, de Vries E, van Waarde A, editors. PET and SPECT in psychiatry. Berlin: Springer; 2014. p. 397-410.

14. Lansing K, Amen DG, Hanks C, Rudy L. High-resolution brain SPECT imaging and eye movement desensitization and reprocessing in police officers with PTSD. J Neuropsychiatry Clin Neurosci. 2005;17:526-32.

15. Pagani M, Högberg G, Salmaso D, Nardo D, Sundin O, Jonsson C, et al. Effects of EMDR psychotherapy on 99mTc-HMPAO distribution in occupation-related post-traumatic stress disorder. Nucl Med Commun. 2007;28:757-65.

16. Lindauer RJL, Booij J, Habraken JBA, van Meijel EPM, Uylings HBM, Olff M, et al. Effects of psychotherapy on regional cerebral blood flow during trauma imagery in patients with post-traumatic stress disorder: a randomized clinical trial. Psychol Med. 2008;38: 543-54.

17. Pagani M, Di Lorenzo G, Verardo AR, Nicolais G, Monaco L, Lauretti G, et al. Neurobiological correlates of EMDR monitoring - an EEG study. PLoS One. 2012;7.

18. Pagani M, Di Lorenzo G, Monaco L, Daverio A, Giannoudas I, La Porta P, et al. Neurobiological response to EMDR therapy in clients with different psychological traumas. Front Psychol. 2015;6.

19. Carletto S, Porcaro C, Settanta C, Vizzari V, Stanizzo MR, Oliva F, et al. Neurobiological features and response to eye movement desensitization and reprocessing treatment of posttraumatic stress disorder in patients with breast cancer. Eur J Psychotraumatol. 2019; 10:1600832.
20. Chiaravalloti A, Pagani M, Micarelli A, Di Pietro B, Genovesi G, Alessandrini $\mathrm{M}$, et al. Cortical activity during olfactory stimulation in multiple chemical sensitivity: a (18)F-FDG PET/CT study. Eur J Nucl Med Mol Imaging. 2015;42:733-40.

21. Zhan X, Yu R. A window into the brain: advances in psychiatric fMRI. Biomed Res Int. 2015;2015:542467.

22. Mitterschiffthaler MT, Ettinger U, Mehta MA, Mataix-Cols D, Williams SCR. Applications of functional magnetic resonance imaging in psychiatry. J Magn Reson Imaging. 2006;23:851-61.

23. Verger A, Guedj E. The renaissance of functional 18F-FDG PET brain activation imaging. Eur J Nucl Med Mol Imaging. 2018;45: 2338-41.

24. Rauch SL, van der Kolk BA, Fisler RE, Alpert NM, Orr SP, Savage $\mathrm{CR}$, et al. A symptom provocation study of posttraumatic stress disorder using positron emission tomography and script-driven imagery. Arch Gen Psychiatry. 1996;53:380-7.

25. Nobili F, Arbizu J, Bouwman F, Drzezga A, Agosta F, Nestor P, et al. European Association of Nuclear Medicine and European Academy of neurology recommendations for the use of brain 18 F-fluorodeoxyglucose positron emission tomography in neurodegenerative cognitive impairment and dementia: Delphi consensus. Eur J Neurol. 2018;25:1201-17.

26. Tai YF, Piccini P. Applications of positron emission tomography (PET) in neurology. J Neurol Neurosurg Psychiatry. 2004;75:66976.

27. Abi-Dargham A, Horga G. The search for imaging biomarkers in psychiatric disorders. Nat Med. 2016;22:1248-55.

28. Colvonen PJ, Glassman LH, Crocker LD, Buttner MM, Orff H, Schiehser DM, et al. Pretreatment biomarkers predicting PTSD psychotherapy outcomes: a systematic review. Neurosci Biobehav Rev. 2017;75:140-56.

29. Hellwig S, Domschke K. Update on PET imaging biomarkers in the diagnosis of neuropsychiatric disorders. Curr Opin Neurol. 2019;32:539.

Publisher's note Springer Nature remains neutral with regard to jurisdictional claims in published maps and institutional affiliations. 